\title{
Effects of Self-Assembled Monolayers with Different Chemical Groups on Ovarian Cancer Cell Line Behavior In Vitro
}

\author{
Jie Li, ${ }^{1,2}$ Ting Guan, ${ }^{1}$ Chenjun Hao, ${ }^{3}$ Lihua $\mathrm{Li}^{4}{ }^{4}$ and Yu Zhang ${ }^{4}$ \\ ${ }^{1}$ Department of Obstetrics and Gynecology, Guangzhou General Hospital of Guangzhou Military Command, \\ Guangzhou 510010, China \\ ${ }^{2}$ Guangzhou University of Chinese Medicine, Guangzhou 510010, China \\ ${ }^{3}$ Panyu Maternal and Child Care Service Centre of Guangzhou, Guangzhou 511400, China \\ ${ }^{4}$ Hospital of Orthopedics, Guangzhou General Hospital of Guangzhou Military Command, Guangzhou 510010, China
}

Correspondence should be addressed to Ting Guan; guantingcn@126.com

Received 10 May 2015; Revised 22 July 2015; Accepted 26 July 2015

Academic Editor: Tanaji Talele

Copyright (c) $2015 \mathrm{Jie} \mathrm{Li} \mathrm{et} \mathrm{al.} \mathrm{This} \mathrm{is} \mathrm{an} \mathrm{open} \mathrm{access} \mathrm{article} \mathrm{distributed} \mathrm{under} \mathrm{the} \mathrm{Creative} \mathrm{Commons} \mathrm{Attribution} \mathrm{License,} \mathrm{which}$ permits unrestricted use, distribution, and reproduction in any medium, provided the original work is properly cited.

In addition to serving as a physical support, the extracellular matrix (ECM) actively influences cell behavior. However, the definitive effects of different chemical structures present in the ECM on cell behavior remain obscure. The current study aimed to investigate the effects of different chemical structures present in the ECM on cellular physiology using the ovarian cancer cell line SKOV-3 as a model. Self-assembled monolayers (SAMs) with different chemical modifications, including methyl (- $\left.\mathrm{CH}_{3}\right), \mathrm{hydroxyl}(-\mathrm{OH})$, amino $\left(-\mathrm{NH}_{2}\right)$, carboxyl $(-\mathrm{COOH})$, and mercapto $(-\mathrm{SH})$ groups, were used as microenvironmental models to explore the effects of different structures on SKOV-3 cells. The cell morphology, cell adhesion, cytotoxicity, and functional alterations in cancer cells cultured on different SAMs were analyzed. The results showed that SKOV-3 cells cultured on $-\mathrm{NH}_{2}$ surfaces exhibited the largest contact area, whereas those on $-\mathrm{CH}_{3}$ surfaces exhibited the smallest contact area and mostly rounded morphologies. Additionally, $-\mathrm{NH}_{2}$ and $-\mathrm{COOH}$ promoted cell proliferation and adhesion, whereas $\mathrm{CH}_{3}$ inhibited adhesion, leading to $\mathrm{Gl}$ arrest during the cell cycle and resulting in cell apoptosis. This study may provide useful information for reconstruction of the ECM and for controlling cell behavior in related areas of study.

\section{Introduction}

The extracellular matrix (ECM) is a network of biological macromolecules that surrounds cells within tissues. In addition to serving as a physical support, the ECM actively influences cell behavior by providing sites for cell adhesion, establishing soluble factor gradients, and forming interfaces between different cell types within a tissue $[1,2]$. Thus, the influence of different chemical structures in the ECM on cell behavior is an important aspect of cell biology.

Self-assembled monolayers (SAMs) are stable, ordered, and closely packed ultrathin membranes that are formed by adsorption of an active surfactant onto a solid surface [3]. Many molecules can be assembled onto these substrates, forming SAMs with different functional groups that affect the integral properties of the SAM surfaces [4-6]. A unique feature of SAMs compared with traditional culture substrates, however, is the fact that functionalized alkane thiolates (terminated with a wide variety of chemical functionalities) can be readily synthesized and efficiently packed into SAMs on $\mathrm{Au}$ [7]. This chemical variability has provided a unique tool to probe the influence of biomaterial surface chemistry on protein adsorption and thus cell interactions with adsorbed proteins. SAMs are routinely used as cell culture substrates to study the influence of adsorbed proteins on cell function. However, studies have underscored the importance of surface chemistry as a key determinant of cell interactions with nonspecifically adsorbed biomolecules, a feature that may have been challenging to assess using traditional polystyrene substrates due to the inherent complexity associated with modifying the surface chemistry of polymeric materials. The observation that surface chemistry 
influences biomolecule adsorption and thus cell interactions with adsorbed biomolecules suggests that spatially patterned surfaces with different chemistries may be used to evaluate the interactions of cells with substrates [8].

Previous studies have used SAMs to evaluate the effects of surface charge, wettability, and cellular behaviors, including the strength of cell adhesion, the spreading of human fibroblasts and human osteoblast-like cells, and the differentiation of mesenchymal stem cells [9-12]. MC3T3E1 osteoblast behavior has been reported to be surface chemistry-dependent and to vary according to the individual functional groups present rather than to general surface properties, such as wettability [9]. Sung et al. have investigated the effects of a range of silane-modified surfaces on the differentiation of human mesenchymal stem cells and have found that changes in the surface chemistry of the glass alter the differentiation potentials of the cells [10]. However, considering that SAMs may be applied in the treatment of diseases, and particularly of malignant cancers, the effects of SAMs with different chemical structures warrant further systematic exploration.

The present study was conducted to investigate cell behaviors in response to different chemical groups using the SAM technique. Our aim was to demonstrate the relationships between different chemical functional groups in the microenvironment and ovarian cancer cells. Our results are meaningful for reconstructing the ECM in vitro and for identifying interactions that occur between the ECM and ovarian cancer cells.

\section{Materials and Methods}

2.1. Preparation of Substrates. Glass wafers (Corning Cat. number 2865-18; $18 \times 18 \mathrm{~mm}$ ) were coated with $\mathrm{Au}(40 \mathrm{~nm})$ after formation of a Ti layer $(40 \mathrm{~nm})$ using an ANELVA L-400EK electron beam evaporator (Canon Anelva Corporation, Kanagawa, Japan). Next, the wafers were cut into $1.0 \mathrm{~cm} \times 0.5 \mathrm{~cm}$ chips, rinsed with ethyl alcohol and tripledistilled water, and cleaned with piranha solution (formed from concentrated $\mathrm{H}_{2} \mathrm{SO}_{4}$ and $30 \% \mathrm{H}_{2} \mathrm{O}_{2}$ ) for $10 \mathrm{~min}$ at room temperature. The wafers were then washed with tripledistilled water in an ultrasonic bath. Finally, the Au substrates were immersed in an ethanol solution containing $1 \mathrm{mM} \mathrm{1-}$ dodecanethiol (- $\mathrm{CH}_{3}$; Sigma, USA), 11-hydroxy-1-undecanethiol (-OH; Sigma, USA), 12-mercaptododecanoic acid ($\mathrm{COOH}$; Sigma, USA), 11-amino-1-undecanethiol hydrochloride (- $\mathrm{NH}_{2}$; Sigma, USA), and 11-undecanedithiol (-SH) for $12 \mathrm{~h}$. Following overnight assembly, the substrates were thoroughly rinsed with triple-distilled water and dried with nitrogen.

2.2. Characterization of the Surfaces. To confirm the presence of the surface modifications, the substrates with different chemical groups were characterized by water contact angle measurement (DataPhysics, Germany). The measurements ( $4 \mathrm{~mL}$ of ultrapure $\mathrm{H}_{2} \mathrm{O}$ ) were performed with an OCA20 contact angle system fitted with a digital camera and were analyzed using in-house image analysis software $[8,9]$.
2.3. Cell Culture. Serous ovarian cancer is the most common ovarian cancer type, accounting for approximately $45 \%$ of all ovarian cancers, and SKOV-3 is one of its representative cell lines [10]. The SKOV-3 cell line was purchased from the American Type Culture Collection (Maryland, USA) and was grown in McCoy's 5A medium (Gibco, Life Technologies, Carlsbad, CA, USA) containing 10\% fetal bovine serum (FBS; HyClone, Thermo, Fremont, CA, USA), $100 \mathrm{U} / \mathrm{mL}$ penicillin, and $100 \mathrm{mg} / \mathrm{mL}$ streptomycin in a humidified $5 \% \mathrm{CO}_{2}$ atmosphere at $37^{\circ} \mathrm{C}$. The medium was changed every 2 days. To investigate the influences of different surfaces on cell growth, modified glass wafers were placed at the bottom of a 24well plate after ultraviolet disinfection for cell inoculation and culture.

Cells were harvested at 75-85\% confluence after 5 days of culture and were then seeded onto SAM surfaces that were modified with $-\mathrm{OH},-\mathrm{COOH},-\mathrm{NH}_{2},-\mathrm{CH}_{3}$, or $-\mathrm{SH}$ chemical functional groups. As a control, an equivalent volume of cells was inoculated into a Corning culture dish.

2.4. Morphological Observations of Cells. The morphologies of cells cultured on the modified SAM surfaces were observed by scanning electron microscopy (SEM; S-3700, HITACHI). After $24 \mathrm{~h}$ of culture, the samples were fixed with $3 \%$ glutaraldehyde for $5 \mathrm{~h}$, rinsed with PBS, and dehydrated in a graded ethanol series (50\%, 70\%, 95\%, and 100\%). Next, the samples were allowed to air-dry and were observed by SEM. Cellular growth was assessed by comparing the morphology of these cells with that of control cells.

2.5. Cell Adhesion Assay. 4,6-Diamidino-2-phenylindole (DAPI) staining was performed to examine the early-stage adhesion of SKOV-3 cells. Cells were cultured on modified $\mathrm{Au}$ surfaces for $30 \mathrm{~min}, 60 \mathrm{~min}$, or $90 \mathrm{~min}$, fixed with $4 \%$ paraformaldehyde for $15 \mathrm{~min}$ at $4^{\circ} \mathrm{C}$, and then washed three times with PBS. Next, they were stained with $300 \mu \mathrm{L}$ DAPI $(10 \mu \mathrm{g} / \mathrm{mL})$ (Roche, Germany) for $30 \mathrm{~min}$ and were photographed using a fluorescence microscope (BX51, Olympus). Five randomly selected fields were counted for each sample. Cell counting was performed by counting the number of nuclei in a certain region, which was selected after comparison between groups.

2.6. Focal Adhesion Assembly. SKOV-3 cells were seeded onto the surfaces with different chemical groups. After culturing for $24 \mathrm{~h}$, cells were fixed with $3.7 \%$ formaldehyde for $10 \mathrm{~min}$ and washed twice with PBS. They were then permeabilized with $0.1 \%$ Triton X-100 in PBS for 3 min, and blocking solution was applied for $10 \mathrm{~min}$. Focal adhesion kinase was stained for 20 min using ActinRed (Keygentec, China) according to the manufacturer's protocol. DAPI was diluted in deionized water to $0.1 \mu \mathrm{g} / \mathrm{mL}$, and staining was carried out for $5 \mathrm{~min}$ at room temperature. The samples were then washed and observed using a fluorescence microscope (BX51, Olympus). Cell adhesion was assessed by observing kinase expression.

2.7. Cytotoxicity Test. Cytotoxicity was examined by 3-(4,5dimethylthiazol-2-yl)-2,5-diphenyltetrazolium bromide (MTT) assay. SKOV-3 cells were cultured in 48-well plates on 
TABLE 1: Effects of SAMs with different chemical groups on the water contact angle $(\bar{x} \pm s)$.

\begin{tabular}{lcccccc}
\hline Sample & Control & $\mathrm{CH}_{3}$ & $\mathrm{OH}$ & $\mathrm{COOH}$ & $\mathrm{NH}_{2}$ & $\mathrm{SH}$ \\
\hline $\bar{x} \pm s$ & $91 \pm 1.63$ & $102.78 \pm 2.66$ & $41.17 \pm 5.97$ & $50.13 \pm 1.69$ & $68.88 \pm 3.64$ & $88.33 \pm 1.98$ \\
\hline$F$ & & 321.5 \\
\hline$p$ & & $<0.001$ & \\
\hline
\end{tabular}

the surfaces modified with the five different chemical groups in a $5 \% \mathrm{CO}_{2}$ incubator at $37^{\circ} \mathrm{C}$. At the indicated time points $(1 \mathrm{~d}, 3 \mathrm{~d}$, and $5 \mathrm{~d}), 30 \mu \mathrm{L}$ of a $5 \mathrm{mg} / \mathrm{mL}$ solution of MTT (Sigma, USA) was added to $300 \mu \mathrm{L}$ culture medium and was incubated for $4 \mathrm{~h}$ at $37^{\circ} \mathrm{C}$. The formazan reaction products were then dissolved in $300 \mu \mathrm{L}$ dimethyl sulfoxide (DMSO) for 20 min. Optical density was determined using an ELISA plate reader (Thermo, Multiskan GO) at $570 \mathrm{~nm}$.

Cell viability was assessed by performing live/dead staining with calcein-AM and PI (Sigma, USA) at $37^{\circ} \mathrm{C}$ for $24 \mathrm{~h}$. Next, cells attached to the SAMs were washed three times with PBS. Images were obtained using a fluorescence microscope (BX51, Olympus), and red-stained and green-stained cells were counted in five randomly selected fields.

2.8. Cell Apoptosis/Necrosis Detection. Apoptosis of SKOV-3 cells was measured using Guava Nexin Reagent (Millipore, USA) according to the manufacturer's protocol. Briefly, cells cultured for $24 \mathrm{~h}$ were collected and resuspended in $100 \mu \mathrm{L}$ of medium supplemented with $1 \%$ FBS. The cells were then incubated with $100 \mu \mathrm{L}$ annexin V-PE and 7-AAD labeling solution (Millipore) for $20 \mathrm{~min}$ at room temperature in the dark. The resultant stained cells were analyzed using a Guava easyCyte 5HT flow cytometer. Simultaneously, the proportion of necrotic cells was synchronously analyzed by flow cytometry based on the amount of cell debris present. Data were analyzed using Guava Nexin Software v2.2.2.

2.9. Cell Cycle Phase Assay. After being cultured for $24 \mathrm{~h}$, SKOV-3 cells were centrifuged at $1000 \mathrm{rpm}$ for $5 \mathrm{~min}$ and were then washed twice with PBS and fixed with $70 \%$ ethanol overnight at $4^{\circ} \mathrm{C}$. Next, the cells were recentrifuged and washed with PBS. Harvested cells were incubated with PI and RNase $\mathrm{A}$ at $37^{\circ} \mathrm{C}$ for $30 \mathrm{~min}$. The cell cycle phases were analyzed using a Guava easyCyte 5HT flow cytometer (Millipore, USA).

2.10. Statistical Analysis. All experiments were repeated three times. All statistical computations were performed with GraphPad Prism 5 software. The data were analyzed using ANOVA, with values considered significantly different at $p<$ 0.05 .

\section{Results}

3.1. Physicochemical Characterization of the SAMs. Characterization of the modified SAM surfaces used in this study via water contact angle measurements has been reported previously $[11,12]$. The $-\mathrm{CH}_{3}$ surface was the most hydrophobic among the tested substrates, with a contact angle of $102.78^{\circ} \pm$ $2.66^{\circ}$. The SAMs terminated with -SH demonstrated a contact angle of $88.33^{\circ} \pm 1.98^{\circ}$, whereas $-\mathrm{COOH}$ and $-\mathrm{NH}_{2}$ formed moderately wettable surfaces, with contact angles of $50.13^{\circ} \pm$ $1.69^{\circ}$ and $68.88^{\circ} \pm 3.64^{\circ}$, respectively. The $-\mathrm{OH}$ surface was the most hydrophilic, with a contact angle of $41.17^{\circ} \pm 5.97^{\circ}$ (Table 1).

3.2. Morphology and Early Adhesion of SKOV-3 Cells. SEM revealed that cell morphology was altered in response to the surfaces with different chemical functional groups (Figure 1). A sparse cell population and spherical cell bodies in a small area were observed for the surfaces with $-\mathrm{CH}_{3}$ terminal groups compared with the other surfaces. In contrast, on the $-\mathrm{NH}_{2}$ surfaces, cells appeared polygonal in shape and were spread out across a large area, with many processes in contact with each other and the surfaces.

Cell adhesion is the first stage of cell-material interaction, and the quality of this stage influences the subsequent proliferation and growth of cells [13]. The numbers of adherent cells are shown in Figure 2. At 60 and 90 min time points, there were fewer adherent cells on the $-\mathrm{CH}_{3}$ surfaces than on the control surfaces (significant at $p<0.01$ ) or on the surfaces with the other terminal chemical groups. There were fewer cells on the - $\mathrm{OH}$ and -SH surfaces than on the control surfaces, but no obvious differences were observed at $90 \mathrm{~min}$. At $90 \mathrm{~min}$, the number of cells seeded on the - $\mathrm{COOH}$ surfaces was obviously increased $(p<0.01)$. In addition, the number of SKOV-3 cells cultured on the $-\mathrm{NH}_{2}$ surfaces was higher during the incubation period compared with the number of cells cultured on the control $(p<0.01)$. Among the surfaces modified with the five chemical groups, adhesion of SKOV-3 cells appeared to be greatly inhibited on the $-\mathrm{CH}_{3}$-modified surfaces.

The differences in initial cell spreading modulated by the different chemical functional groups were confirmed by analysis of focal adhesion (Figure 3). Actin in the focal adhesion plaques was indicated by a red color. Both focal adhesion formation and cell size differed among SKOV-3 cells cultured on the surfaces modified with the different chemical functional groups. Cells on the -OH-modified surfaces had similar diameters as those on the control surfaces (without modification) (between $30 \mu \mathrm{m}$ and $50 \mu \mathrm{m}$ ). On the $-\mathrm{CH}_{3}$ modified surfaces, the formation of cellular focal adhesions was significantly inhibited. Cell nuclei were not clearly visible, and few focal adhesions and actin stress fibers were observed. Cells on the $-\mathrm{CH}_{3}$ and $-\mathrm{SH}$ surfaces were rounded, with sizes of approximately $20-30 \mu \mathrm{m}$, whereas those on the surfaces 

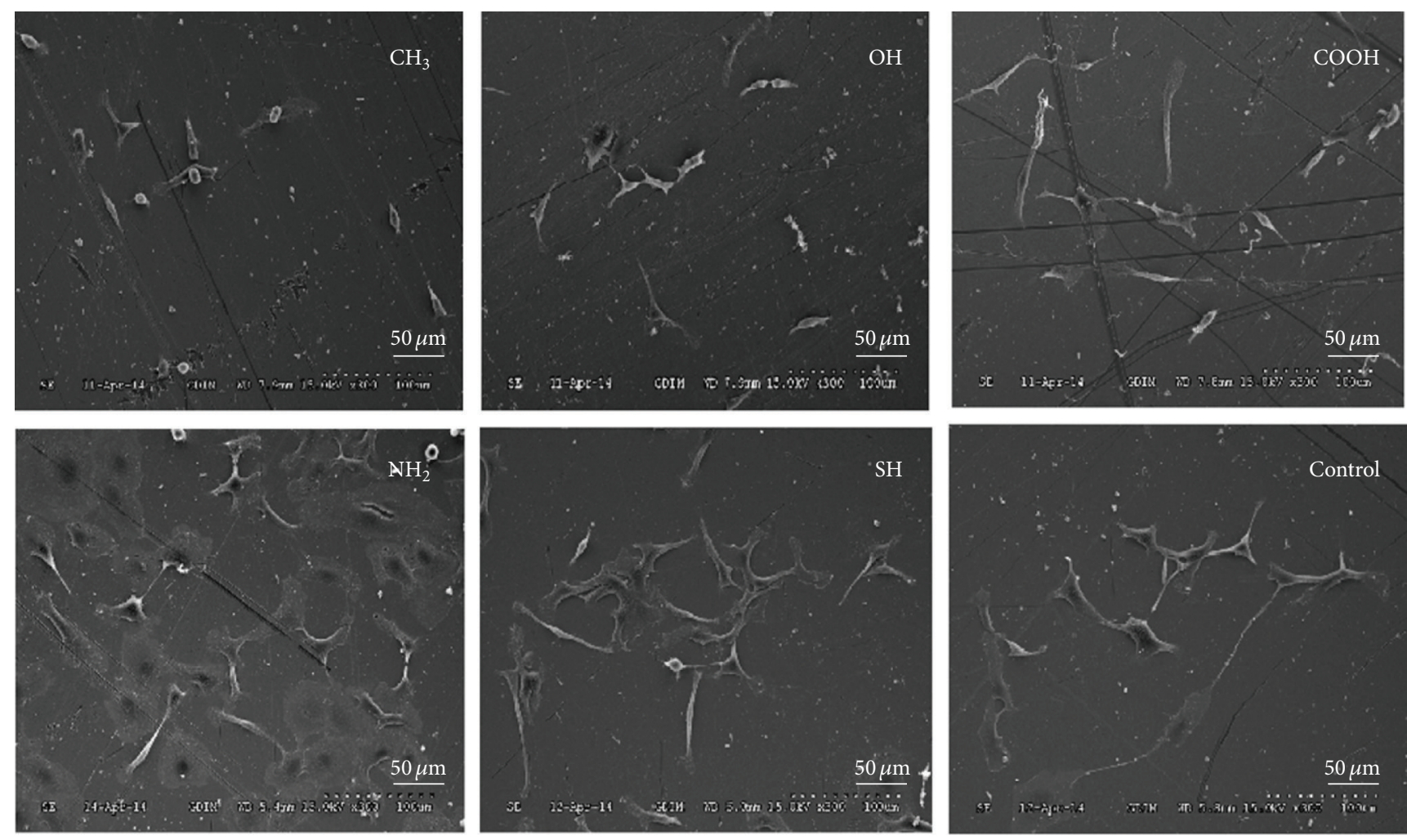

FIGURE 1: SEM photographs of SKOV-3 cells cultured on surfaces with different chemical functional groups for $24 \mathrm{~h}$. Scale bar $=50 \mu \mathrm{m}$.

modified with $-\mathrm{COOH}$ or $-\mathrm{NH}_{2}$ were polygonal and approximately $40-60 \mu \mathrm{m}$ wide.

3.3. Cytotoxicity Test. The results of MTT assay of SKOV3 cells cultured on surfaces modified with the different chemical groups for $1 \mathrm{~d}, 3 \mathrm{~d}$, or $5 \mathrm{~d}$ are shown in Figure 4 . From day 1 to day 3 , there was a nonsignificant difference in the proliferation of SKOV-3 cells on the different surfaces. On day 5 , cells on the $-\mathrm{CH}_{3}$ surfaces showed the lowest proliferation rate among all of the groups (versus the control, $p<0.01$ ). However, the number of cells on the $-\mathrm{NH}_{2}$ surfaces significantly increased compared with that of cells on the control surfaces. The - $\mathrm{OH},-\mathrm{COOH},-\mathrm{NH}_{2}$, and $-\mathrm{SH}$ modifications appeared to promote cell proliferation over a longer culture period, but their proliferation rates did not significantly differ compared with that of the control. The proliferation capacities of SKOV-3 cells on the SAMs with the different chemical groups can be ordered as follows: $-\mathrm{NH}_{2}>$ $-\mathrm{COOH}>-\mathrm{OH}>-\mathrm{SH}>-\mathrm{CH}_{3}$.

3.4. Live/Dead Assay. The effects of the different chemical groups on cytotoxicity were also evaluated by live/dead viability/cytotoxicity staining. Representative fluorescence micrographs were chosen for visualization of live (green) and dead (red) cells, as shown in Figure 5. In the control group (without modification), no nonviable (red) cells were observed. Rare viable (green) cells and several nonviable (red) cells were observed on the surfaces with $-\mathrm{CH}_{3}$ groups after incubation for $24 \mathrm{~h}$. No nonviable cells and denser populations of viable cells were observed on the $-\mathrm{OH},-\mathrm{COOH}$, and $-\mathrm{NH}_{2}$ surfaces. There were only two nonviable cells on the - $\mathrm{SH}$ surface. These observations indicated that the $-\mathrm{CH}_{3}$ functional group induced cell toxicity, whereas the $-\mathrm{NH}_{2}$ and $-\mathrm{COOH}$ groups produced little cell toxicity.

3.5. Cell Apoptosis Assay. Abnormal cell apoptosis and cell death are the characteristics of cancer cells evaluated using annexin V-PE and 7-ADD. As shown in Figure 6, approximately $7.5 \%$ of cells cultured on the $-\mathrm{CH}_{3}$-modified surfaces were apoptotic $(p<0.01)$ as were approximately $10 \%$ of those cultured on the -OH-modified surfaces $(p<0.01)$. Both of these proportions were significantly greater than that of the control (3\%). The rate of death of cells cultured on the $\mathrm{SH}$-modified surfaces did not significantly differ from that of cells cultured on the control surfaces. The $-\mathrm{NH}_{2}$ group clearly decreased SKOV-3 cell necrosis, with $8 \%$ dead cells compared with $12.5 \%$ dead control cells $(p<0.05)$.

3.6. Cell Cycle Assay. The results of cell cycle analysis of SKOV-3 cells cultured on the surfaces modified with the different chemical groups are shown in Figure 7. The percentages of SKOV-3 cells in the mitotic phase (G2/M) during 

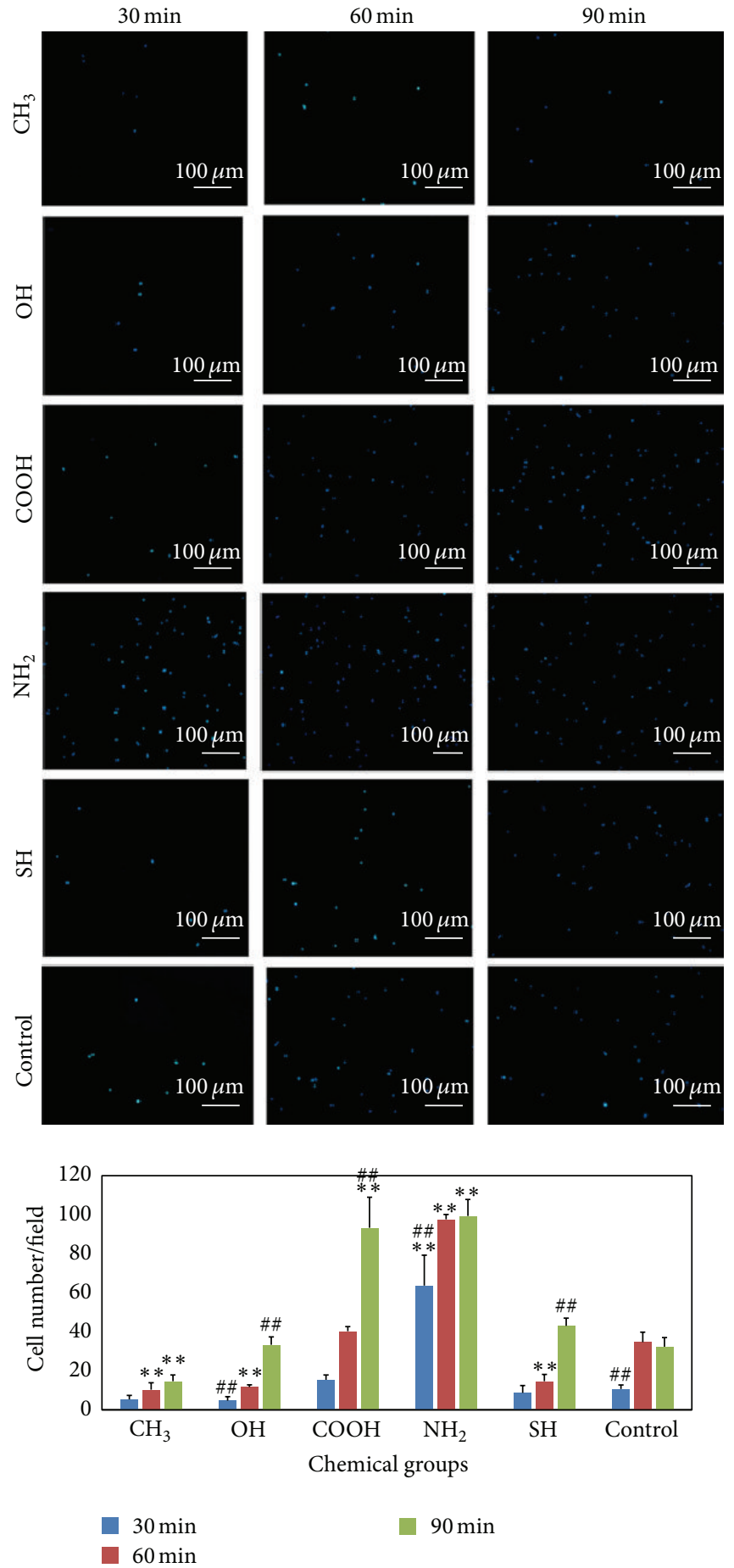

FIGURE 2: Cell counts for adherent SKOV-3 cells cultured on substrates containing different chemical groups. Cells were stained with DAPI and observed by fluorescence microscopy after $30 \mathrm{~min}, 60 \mathrm{~min}$, or $90 \mathrm{~min}$. Scale bar $=100 \mu \mathrm{m}$. One symbol, $p<0.05 ; 2 \mathrm{symbols}, p<0.01$; ${ }^{*}$ compared with the control at the same time point; ${ }^{*}$ compared with the same substrate at 60 min. 

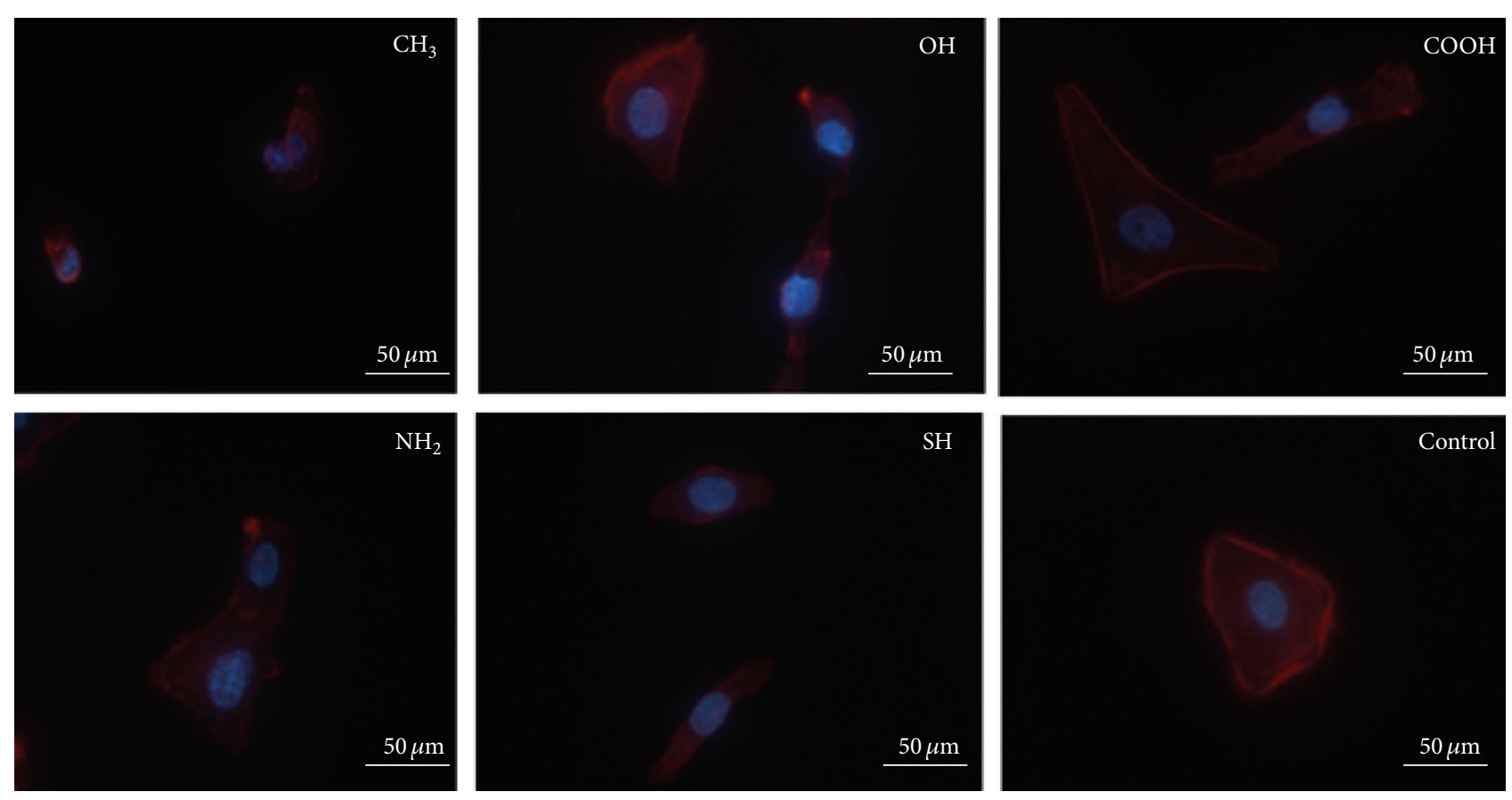

FIGURE 3: Focal adhesions of SKOV-3 cells cultured on surfaces with different chemical functional groups for $24 \mathrm{~h}$. Scale bar $=50 \mu \mathrm{m}$.

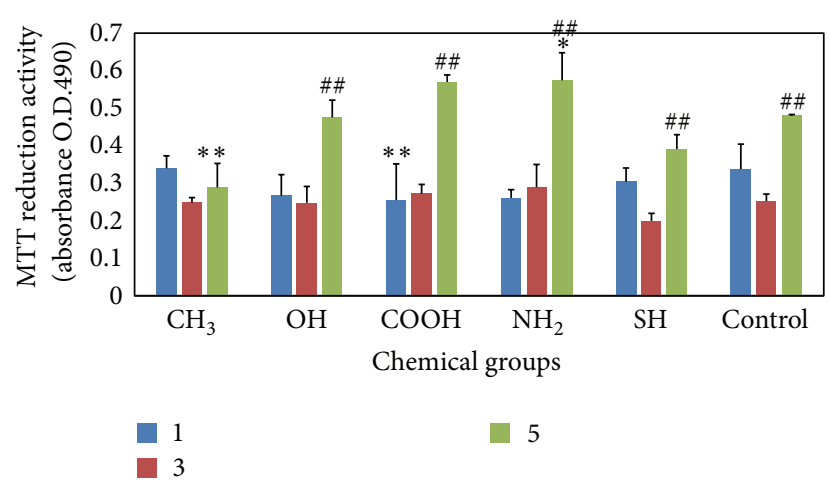

FIGURE 4: MTT reduction by SKOV-3 cells cultured on surfaces modified with different chemical groups for $1 \mathrm{~d}, 3 \mathrm{~d}$, or $5 \mathrm{~d}$. The error bars represent the mean $+\mathrm{SD}$ for $n=3$. One symbol, $p<0.05 ; 2$ symbols, $p<0.01$; * compared with the control on the same day; \# compared with the same substrate on day 3.

culturing on the $-\mathrm{CH}_{3}$ - and -OH-modified surfaces were $11.94 \%$ and $13.50 \%$, respectively, which were significantly lower than that for cells cultured on the control surfaces (15.99\%) (both $p<0.01$ ). These findings indicated that the $-\mathrm{CH}_{3}$ chemical group inhibited the S-to-G2 phase cell cycle transition, leading to G1 arrest. Compared with cells on the control surfaces, those on the surfaces modified with $-\mathrm{OH}$,
$-\mathrm{NH}_{2}$, and $-\mathrm{COOH}$ groups did not significantly differ in the proportions of cells in the mitotic phase $(\mathrm{G} 2 / \mathrm{M})$, which were $15.11 \%, 14.89 \%$, and $15.43 \%$, respectively (all $p>0.05$ ).

\section{Discussion}

This study revealed that the morphology, adhesion, proliferation, and apoptosis of SKOV-3 cells differed in response to different chemical groups.

Surface wettability was shown to be an important factor in protein adhesion to biomaterial surfaces. The best surfaces for cell adhesion and growth have the most suitable hydrophilic/hydrophobic balance. The optimal value varies for different types of cells. Excessively hydrophilic surfaces are not conducive to protein adsorption. In this paper, the water contact angle measurements revealed that $-\mathrm{CH}_{3}$ groups cause surfaces to be hydrophobic and that $-\mathrm{NH}_{2}$ and $-\mathrm{COOH}$ cause them to be moderately wettable, whereas - $\mathrm{OH}$-modified surfaces are the most hydrophilic. SKOV-3 cells assumed a polygonal shape when cultured on surfaces with $-\mathrm{NH}_{2}$ terminal functional groups, and the cells expanded to larger areas and extended more processes on these surfaces than on the other surfaces. Our results showed that both $-\mathrm{COOH}$ and $-\mathrm{NH}_{2}$ terminal functional groups promoted adhesion of SKOV-3 cells, which is consistent with the findings of Jal et al. [14].

It has been well established that the behavior of adherent cells is related to their shapes [15-20]. Cells with 

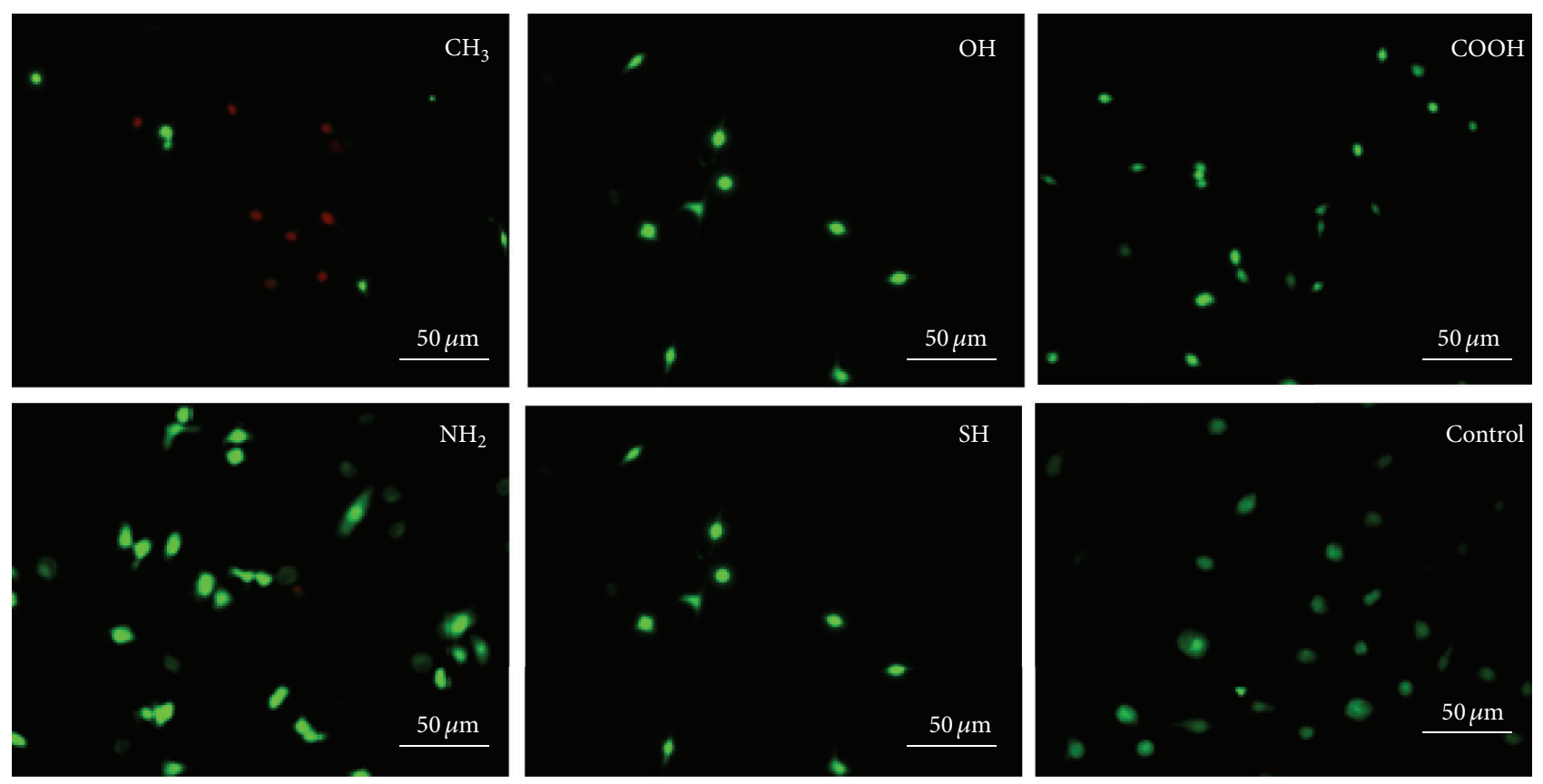

FIGURE 5: Fluorescence micrographs of live/dead dye-stained SKOV-3 cells cultured on substrates modified with different chemical groups for $24 \mathrm{~h}$. Scale bar $=50 \mu \mathrm{m}$. Green cells are viable, and red cells are nonviable.

nonflattened and round shapes are likely to become apoptotic, and under these conditions cell proliferation is usually negatively affected $[19,21]$. In contrast, healthy cells have wellspread and polygonal shapes $[16,20]$. In the current study, the proliferative capacities of SKOV-3 cells on the SAMs with the different chemical groups can be ordered as follows: $-\mathrm{NH}_{2}>$ $-\mathrm{COOH}>-\mathrm{OH}>-\mathrm{SH}>-\mathrm{CH}_{3}$. The $-\mathrm{NH}_{2}$ - and $-\mathrm{COOH}-$ functionalized surfaces promoted SKOV-3 cell proliferation, whereas the $-\mathrm{CH}_{3}$ - and - $\mathrm{SH}$-functionalized surfaces inhibited proliferation. Viability/cytotoxicity staining also indicated that the $-\mathrm{CH}_{3}$ group was somewhat toxic to cells. In addition, all of the surfaces except for the -SH-coated surfaces caused an increase in the proportion of necrotic SKOV-3 cells. This phenomenon has been previously reported in the literature, and the underlying mechanism warrants further exploration in the future.

Our results indicated that the $-\mathrm{CH}_{3}$ group may have caused apoptosis by inhibiting the S-to-G2 phase transition of the cell cycle, leading to $\mathrm{G} 1$ arrest, whereas the $-\mathrm{NH}_{2}$ group caused an obvious decrease in SKOV-3 cell necrosis. These results are consistent with the relationship between cell morphology and cell behavior discussed above.

Chemical groups play an important role in intercellular communication $[5,22]$. Previous studies have elucidated the different effects of chemical functional groups on tumor cells [23]. The -OH group has been reported to have positive effects on macrophage adhesion [13]. Further, human osteoblastoma cells show much better adhesion and spreading across larger areas on surfaces terminated with $-\mathrm{COOH},-\mathrm{OH}$, or $-\mathrm{NH}_{2}$ than on hydrophobic surfaces. Yan et al. have shown that MCF-7 cells cultured on -SH- or -OH-modified substrates have the lowest viability and migratory capacity [24]. The different interactions of chemical functional groups with cells should play vital roles in this respect. In addition, there may be communication between $-\mathrm{CH}_{3}$ groups and ovarian cancer cells.

The results of our study suggest that $-\mathrm{CH}_{3}$ inhibits proliferation and adhesion of cells and promotes apoptosis and necrosis of tumor cells, whereas $-\mathrm{NH}_{2}$ and -COOH promote cell adhesion. However, how cells identify the physical and chemical characteristics of the ECM has not been reported to the best of our knowledge. Presumably, adhesion and migration of cells primarily depend upon interactions between the molecules on their surfaces (particularly integrin) and those on the surfaces of vectors (the Arg-Gly-Asp (RGD) repeat sequence of fibronectin in the ECM predominates in vivo) [25]. Arginine contains NH residues, and aspartate contains $\mathrm{COOH}$ residues. Nevertheless, further studies are needed to understand the signaling pathways by which cell behavior is affected by the chemical groups present on a substrate.

This study has some limitations. First, because it was a preliminary study and the surfaces used are not produced and distributed on a large scale, we did not perform strict verification of the uniformity of the glass wafers (although they were from the same batch). Second, we did not use synchronous cells due to a lack of a sufficient number of synchronized 

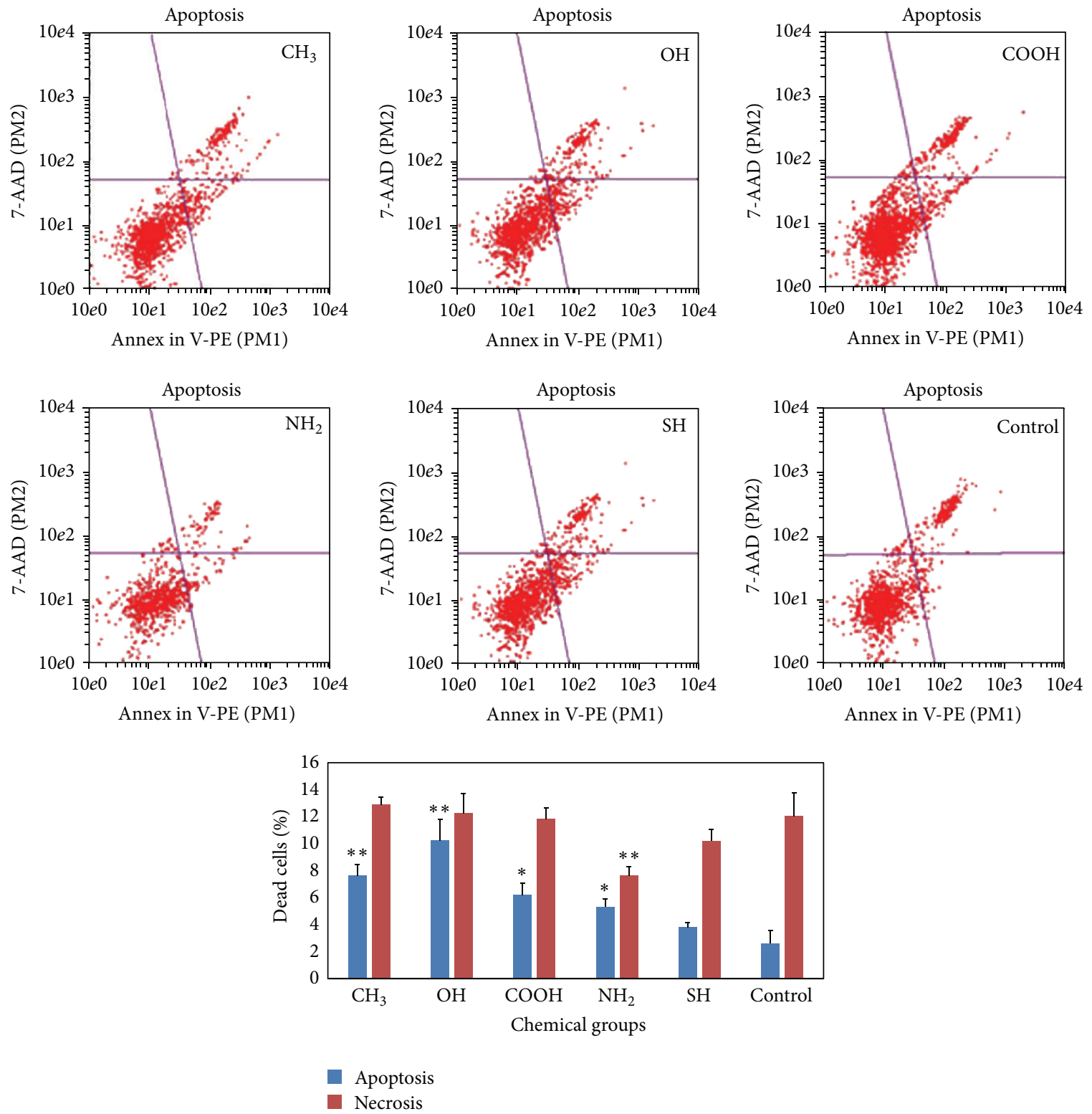

FIGURE 6: SKOV-3 cells were cultured on substrates with different chemical groups for $24 \mathrm{~h}$. The percentage of annexin V(+)/PI( $(-)$ cells indicates apoptosis. The percentage of annexin $\mathrm{V}(+) / \mathrm{PI}(+)$ cells indicates necrosis. One symbol, $p<0.05 ; 2$ symbols, $p<0.01 ;{ }^{*}$ compared with the control.

cells, which may have influenced the outcomes of this study. Third, the experiments in the present study were performed using the ovarian cancer cell line SKOV-3. Whether our findings are applicable to other cell lines requires further exploration.

This study investigated how the fate of SKOV-3 cells, including their morphology, adhesion, proliferation, and apoptosis, was affected by the presence of the $-\mathrm{CH}_{3},-\mathrm{OH}$, $-\mathrm{COOH},-\mathrm{NH}_{2}$, and $-\mathrm{SH}$ groups on culture substrates. $-\mathrm{NH}_{2}-$ terminated surfaces may support preferential binding of actin to increase cell adhesion because cells cultured on $-\mathrm{NH}_{2}$ grew across a larger area than those on the other surfaces. Further, the $-\mathrm{CH}_{3}$-terminated surfaces significantly inhibited cell proliferation due to poor cell adhesion, high cytotoxicity, and promotion of apoptosis. These results highlight the important effects of the chemical groups present on substrates on the fate of cancer cells and suggest that cell culture substrate modifications are useful for controlling cell behavior in vitro.

\section{Conflict of Interests}

The authors declare that there is no conflict of interests regarding the publication of this paper. 

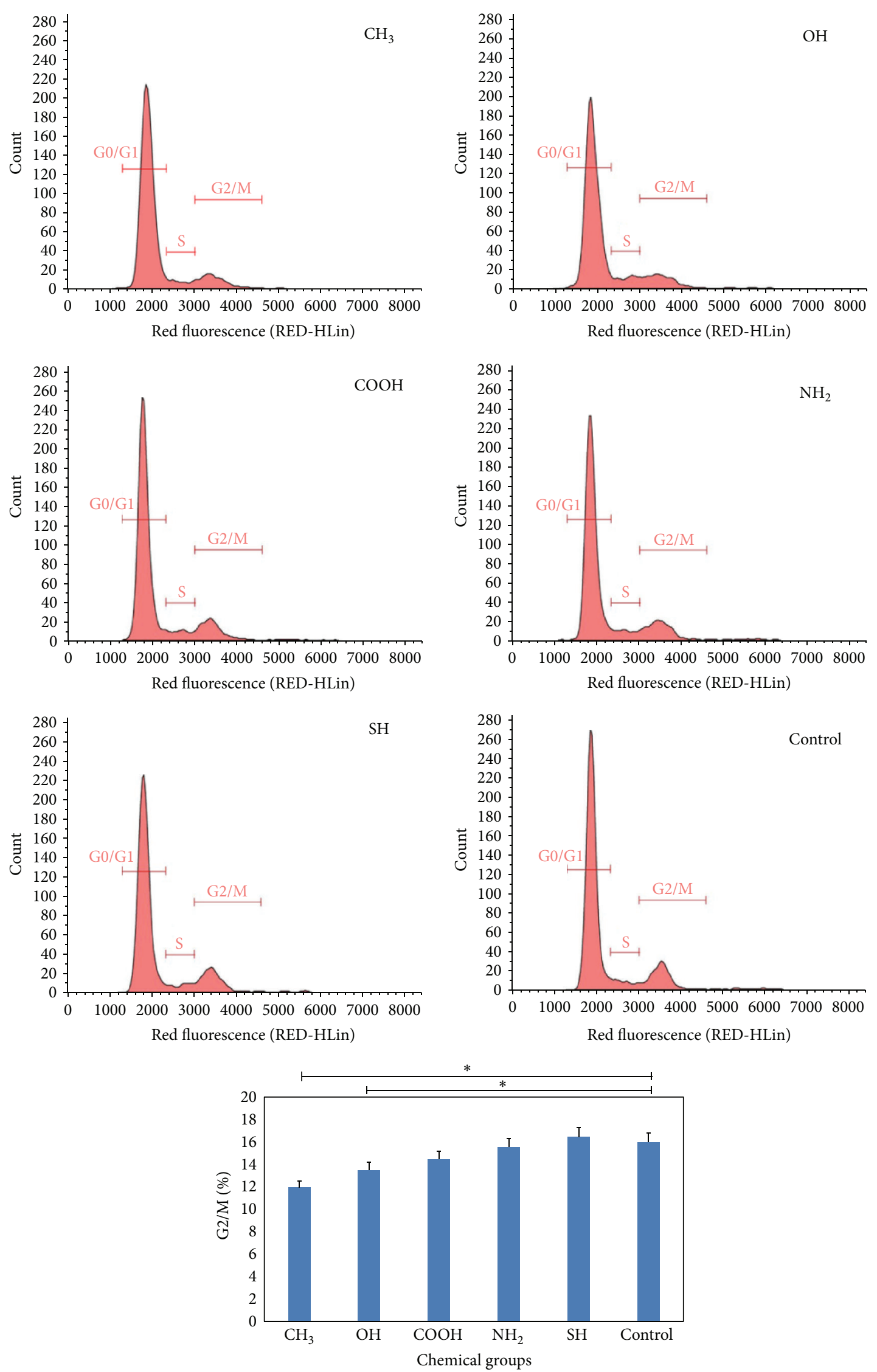

FIGURE 7: Cell cycle assay of asynchronous SKOV-3 cells cultured on substrates with different chemical groups for $24 \mathrm{~h}$ and analyzed by flow cytometry. ${ }^{*} p<0.05$. 


\section{Acknowledgments}

The authors thank Professor Zhang at the Herbarium of the Guangzhou Institute of Microbiology for the use of the SEM. This work was supported by Cancer Foundation Projects of China (no. S2012010) and the National Natural Science Foundation of China (nos. 81271957 and 81272507).

\section{References}

[1] C. J. Sobers, S. E. Wood, and M. Mrksich, "A gene expressionbased comparison of cell adhesion to extracellular matrix and RGD-terminated monolayers," Biomaterials, vol. 52, pp. 385394, 2015.

[2] T. Hayashi, "Extracellular matrix and its biological function," Tanpakushitsu Kakusan Koso, vol. 37, no. 13, pp. 2269-2278, 1992.

[3] P. Gutfreund, O. Bäumchen, R. Renate Fetzer et al., "Solid surface structure affects liquid order at the polystyrene-selfassembled-monolayer interface," Physical Review E: Statistical, Nonlinear, and Soft Matter Physics, vol. 87, no. 1, Article ID 012306, 2013.

[4] A. E. Koser, N. C. Keim, and P. E. Arratia, "Structure and dynamics of self-assembling colloidal monolayers in oscillating magnetic fields," Physical Review E: Statistical, Nonlinear, and Soft Matter Physics, vol. 88, no. 6, Article ID 062304, 2013.

[5] N. Faucheux, R. Schweiss, K. Lützow, C. Werner, and T. Groth, "Self-assembled monolayers with different terminating groups as model substrates for cell adhesion studies," Biomaterials, vol. 25, no. 14, pp. 2721-2730, 2004.

[6] X. Liu, J. He, S. Zhang, X.-M. Wang, H.-Y. Liu, and F.-Z. Cui, "Adipose stem cells controlled by surface chemistry," Journal of Tissue Engineering and Regenerative Medicine, vol. 7, no. 2, pp. 112-117, 2013.

[7] T. Yamaguchi, H. Okawa, K. Hashimoto, and K. Kajikawa, "Formation process of self-assembled monolayer on gold nanosphere probed by second harmonic generation," Langmuir, vol. 26, no. 18, pp. 14543-14547, 2010.

[8] Y. Adiguzel and H. Kulah, "Studies on visual detection and surface modification testing of glass microfiber filter paper based biosensor," Biosensors and Bioelectronics, vol. 54, pp. 2734, 2014.

[9] A. E. Kovalev, K. Dening, B. N. Persson, and S. N. Gorb, "Surface topography and contact mechanics of dry and wet human skin," Beilstein Journal of Nanotechnology, vol. 5, pp. 1341-1348, 2014.

[10] P.-L. Sung, Y.-H. Chang, K.-C. Chao, and C.-M. Chuang, "Global distribution pattern of histological subtypes of epithelial ovarian cancer: a database analysis and systematic review," Gynecologic Oncology, vol. 133, no. 2, pp. 147-154, 2014.

[11] Y. Tamada and Y. Ikada, "Fibroblast growth on polymer surfaces and biosynthesis of collagen," Journal of Biomedical Materials Research, vol. 28, no. 7, pp. 783-789, 1994.

[12] J. H. Lee, H. W. Jung, I.-K. Kang, and H. B. Lee, "Cell behaviour on polymer surfaces with different functional groups," Biomaterials, vol. 15, no. 9, pp. 705-711, 1994.

[13] Ø. Halskau, S. Volden, A. C. Calvo, A. Martinez, and W. R. Glomm, "Adsorption and bioactivity of tyrosine hydroxylase on gold surfaces and nanoparticles," Protein and Peptide Letters, vol. 17, no. 11, pp. 1376-1382, 2010.
[14] P. K. Jal, S. Patel, and B. K. Mishra, "Chemical modification of silica surface by immobilization of functional groups for extractive concentration of metal ions," Talanta, vol. 62 , no. 5 , pp. 1005-1028, 2004.

[15] Y.-J. Ren, H. Zhang, H. Huang et al., "In vitro behavior of neural stem cells in response to different chemical functional groups," Biomaterials, vol. 30, no. 6, pp. 1036-1044, 2009.

[16] L.-M. Postovit, E. A. Seftor, R. E. B. Seftor, and M. J. C. Hendrix, "Influence of the microenvironment on melanoma cell fate determination and phenotype," Cancer Research, vol. 66, no. 16, pp. 7833-7836, 2006.

[17] A. Cucina, P.-M. Biava, F. D’Anselmi et al., "Zebrafish embryo proteins induce apoptosis in human colon cancer cells (Caco2)," Apoptosis, vol. 11, no. 9, pp. 1617-1628, 2006.

[18] L. Chen, Z. Xiao, Y. Meng et al., "The enhancement of cancer stem cell properties of MCF-7 cells in 3D collagen scaffolds for modeling of cancer and anti-cancer drugs," Biomaterials, vol. 33, no. 5, pp. 1437-1444, 2012.

[19] D. E. Ingber, "Can cancer be reversed by engineering the tumor microenvironment?" Seminars in Cancer Biology, vol. 18, no. 5, pp. 356-364, 2008.

[20] M. H. Lee, P. Ducheyne, L. Lynch, D. Boettiger, and R. J. Composto, "Effect of biomaterial surface properties on fibronectin$\alpha_{5} \beta_{1}$ integrin interaction and cellular attachment," Biomaterials, vol. 27, no. 9, pp. 1907-1916, 1907.

[21] H. Lee, Y. Jang, J. Seo, J.-M. Nam, and K. Char, "Nanoparticlefunctionalized polymer platform for controlling metastatic cancer cell adhesion, shape, and motility," ACS Nano, vol. 5, no. 7, pp. 5444-5456, 2011.

[22] C. A. Scotchford, C. P. Gilmore, E. Cooper, G. J. Leggett, and S. Downes, "Protein adsorption and human osteoblast-like cell attachment and growth on alkylthiol on gold self-assembled monolayers," Journal of Biomedical Materials Research, vol. 59, no. 1, pp. 84-99, 2002.

[23] J. MacIel, M. I. Oliveira, R. M. Gonalves, and M. A. Barbosa, "The effect of adsorbed fibronectin and osteopontin on macrophage adhesion and morphology on hydrophilic and hydrophobic model surfaces," Acta Biomaterialia, vol. 8, no. 10, pp. 3669-3677, 2012.

[24] H. Yan, S. Zhang, J. He et al., "Self-assembled monolayers with different chemical group substrates for the study of MCF-7 breast cancer cell line behavior," Biomedical Materials, vol. 8, no. 3, Article ID 035008, 2013.

[25] J. E. Schwarzbauer and D. W. DeSimone, "Fibronectins, their fibrillogenesis, and in vivo functions," Cold Spring Harbor Perspectives in Biology, vol. 3, no. 7, 2011. 

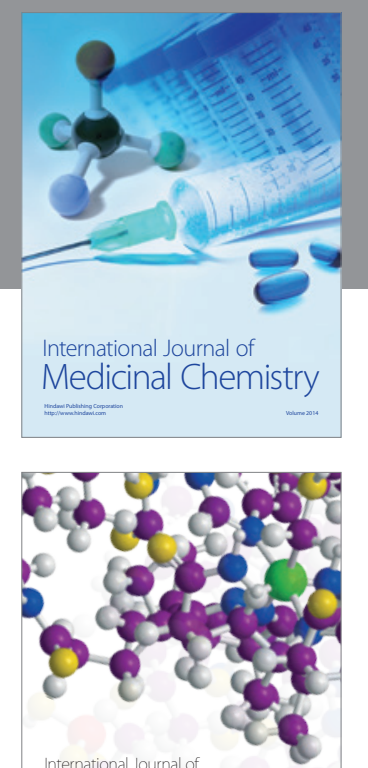

\section{Carbohydrate} Chemistry

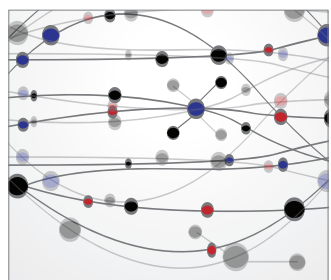

The Scientific World Journal
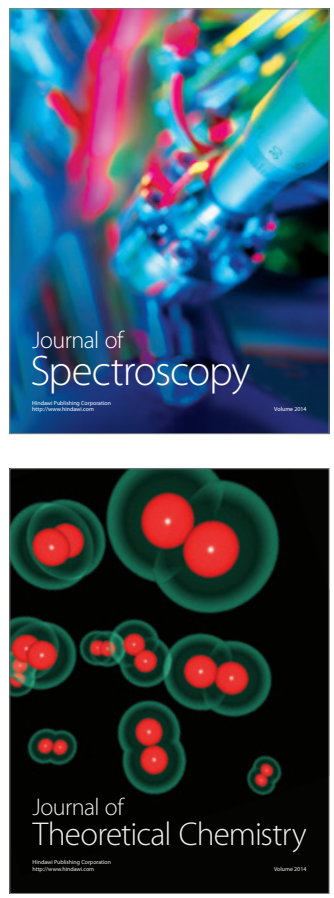
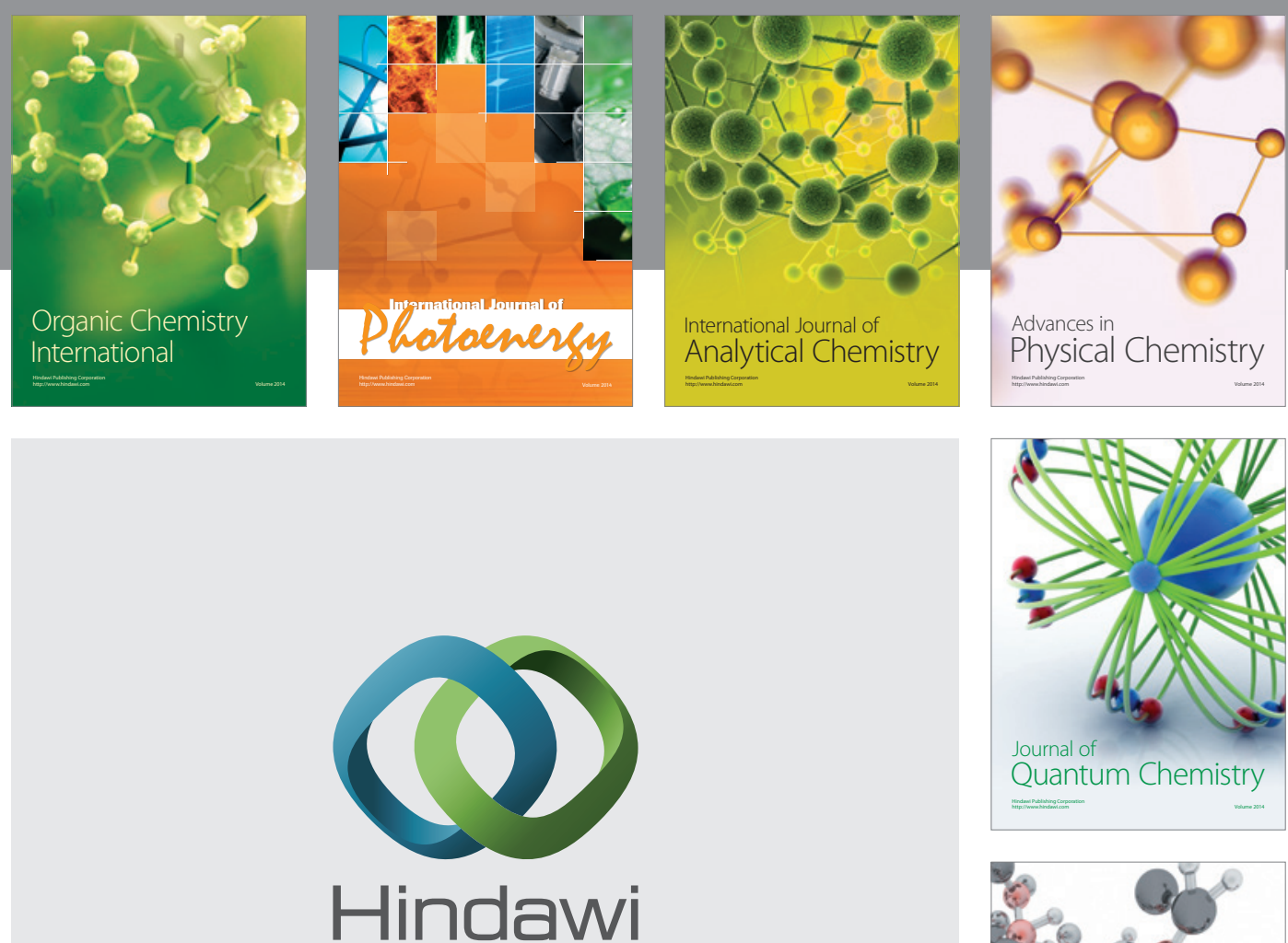

Submit your manuscripts at

http://www.hindawi.com

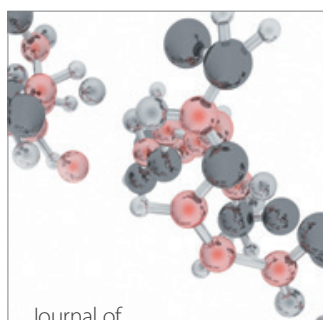

Analytical Methods

in Chemistry

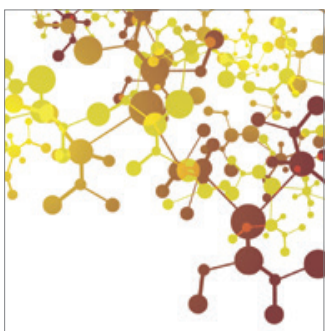

Journal of

Applied Chemistry

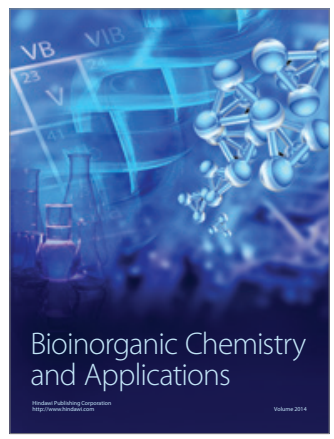

Inorganic Chemistry
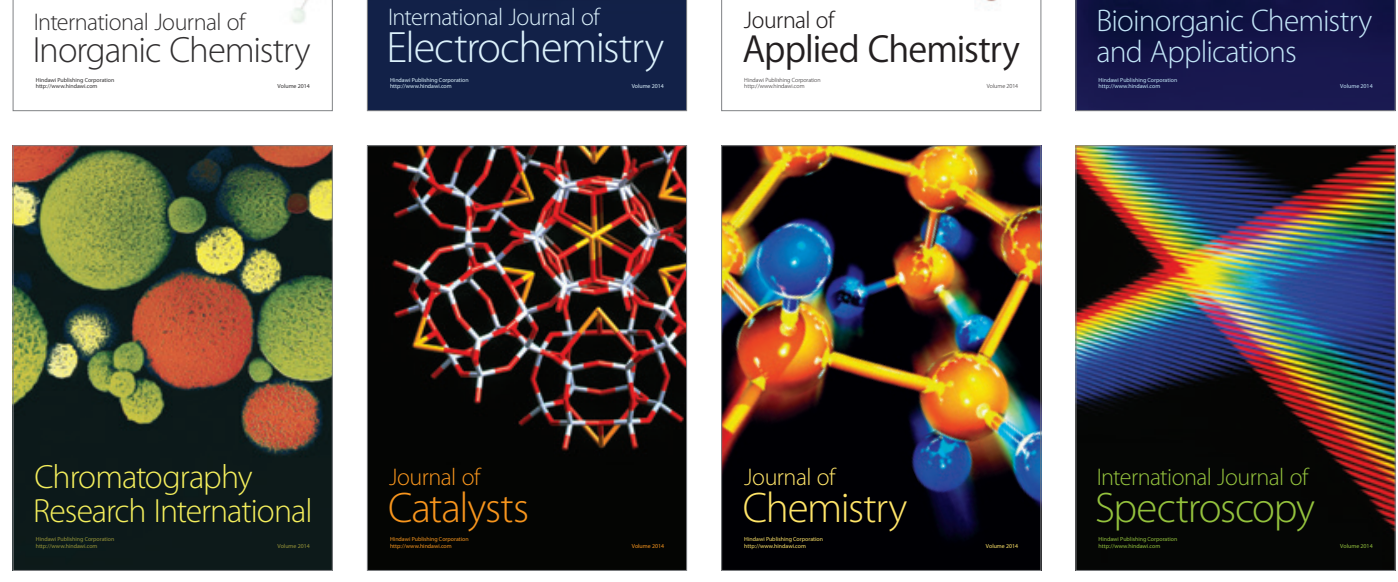